\title{
Prescription Patterns of Chinese Medicinal Herbs in Switzerland
}

\author{
Sabine D. Klein ${ }^{a}$ Dominic van der Zypen ${ }^{b}$ Simon Becker ${ }^{c, d}$ \\ a Medical Practice for Acupuncture, Effretikon, \\ ${ }^{b}$ Allianz Suisse Insurance, Zurich, \\ 'Medical Practice for Acupuncture and Chinese Medicine, Wädenswil, \\ dLian Chinaherb AG, Wollerau, Switzerland
}

\section{Keywords}

Chinese herbal medicine · Prescription patterns · Traditional Chinese Medicine, TCM

\section{Summary}

Introduction: Chinese medicine is increasingly popular in Switzerland and is often used complementarily to conventional medicine. However, little is known about the habits of prescription of Chinese medicinal herbs in Switzerland. Material and Methods: A random sample of 1,053 prescriptions was drawn from the database of Lian Chinaherb AG, Switzerland, and analysed according to the most frequently used individual herbs and classical formulas (all ingredients are referred to as herbs for reasons of simplicity, although not all products are parts of plants). Average number of single herbs and daily dosage of granules (the most popular pharmaceutical form) per prescription were calculated. Cluster analysis was applied to identify common combinations of herbs. Results: The herbs dang gui (Angelicae Sinensis Radix), fu ling (Poria), bai shao (Paeoniae Radix Alba), and gan cao (Glycyrrhizae Radix et Rhizoma) as well as the formulas gui pi tang (Restore the Spleen Decoction) and xiao yao san (Rambling Powder) were used most frequently. The average number of herbs per prescription was 12 , and the average daily dosage of granules was $8.7 \mathrm{~g}$. Cluster analysis confirmed the usage of known herb pairs, e.g. ban xia (Pinelliae Rhizoma) and chen pi (Citri Reticulatae Pericarpium), and identified combinations of herbs in known formulas. Discussion: This study provides a first overview of the application of traditional Chinese medicinal herbs and prescriptions in Switzerland. Future studies may aim to evaluate the simultaneous use of conventional drugs and Chinese medicinal herbs in order to increase knowledge about their safety.

\section{Schlüsselwörter}

Chinesische Arzneitherapie · Verschreibungsmuster · Traditionelle Chinesische Medizin, TCM

\section{Zusammenfassung}

Verschreibungsmuster chinesischer Arzneien in der Schweiz

Hintergrund: Die Chinesische Medizin erfährt eine zunehmende Beliebtheit in der Schweiz und wird häufig komplementär zur konventionellen Medizin angewandt. Allerdings ist wenig über die Praxis der Verschreibung chinesischer Arzneimittel in der Schweiz bekannt. Material und Methoden: Eine zufällige Stichprobe von 1053 Verschreibungen wurde aus der Datenbank der Lian Chinaherb AG, Schweiz, gezogen und auf die am häufigsten verwendeten Arzneien und Rezepturen hin analysiert. Die durchschnittliche Anzahl von Einzelarzneien und die Tagesdosis an Granulat (der beliebtesten Darreichungsform) pro Verschreibung wurden berechnet. Mittels Clusteranalyse wurden gebräuchliche Arzneikombinationen identifiziert. Ergebnisse: Am häufigsten wurden die Arzneien dang gui (Angelicae Sinensis Radix), fu ling (Poria), bai shao (Paeoniae Radix Alba) und gan cao (Glycyrrhizae Radix et Rhizoma) sowie die Rezepturen gui pi tang (Dekokt, das die Milz wiederherstellt) und xiao yao san (Umherstreifen-Pulver) verwendet. Die durchschnittliche Anzahl Arzneien pro Verschreibung betrug 12, die durchschnittliche Tagesdosis an Granulat 8,7 g. Die Clusteranalyse bestätigte die Verwendung bekannter Arzneipaare, wie z.B. ban xia (Pinelliae Rhizoma) und chen pi (Citri Reticulatae Pericarpium), und ermittelte Elemente bekannter Rezepturen. Diskussion: Diese Studie gibt einen ersten Überblick über die Anwendung traditioneller chinesischer Arzneien und Verschreibungen in der Schweiz. In zukünftigen Studien kann die gleichzeitige Verwendung von konventionellen Medikamenten und chinesischen Arzneien untersucht werden, um das Wissen über die Sicherheit solcher Kombinationen zu vergrössern.

$\begin{array}{ll}\text { KARGER } & \text { ( ) 2010 S. Karger GmbH, Freiburg } \\ \text { Fax +49761 } 4520714 & \text { Accessible online at: } \\ \text { Information@Karger.de } & \text { www.karger.com/szg } \\ \text { wwwkarger.com } & \end{array}$

Dr. sc. nat., dipl. Akupunkteurin Sabine D. Klein

Praxis für Akupunktur

Märtplatz 3, 8307 Effretikon, Switzerland

Tel. +4178 8023300

praxis@effipunktur.ch 


\section{Introduction}

In May 2009, two-thirds of the Swiss people voted to include complementary medicine in the Swiss constitution. This demonstrates the popularity of complementary and alternative medicine (CAM) in Switzerland [1]. Moreover, voluntary health insurances, which about $65 \%$ of the population have, pay for most forms of CAM, and $14 \%$ of the physicians in primary care are qualified in at least one CAM discipline [2].

Since a revision in the Swiss medicinal act in 2001, CAM substances including Chinese herbs and homoeopathic remedies have been officially classified as medicinal substances. Therefore, the Swiss Agency for Therapeutic Products, Swissmedic, is now responsible for their quality and safety, and all Chinese medicines sold in Switzerland must fulfil quality requirements for medicinal substances defined by Swissmedic [3]. Even though these quality requirements put much pressure on companies and pharmacies selling Chinese medicines, they are also responsible for raising the quality level of Chinese medicines in Switzerland to one of the best worldwide and thus making Chinese medicine safer (for safety assessment report, see [4]).

The standard prescriptive methodology of Chinese medicine is the individualised patient prescription (for introduction, see [5]). Currently, around 4,000-5,000 individual prescriptions are issued weekly by the estimated 500 medical and non-medical practitioners with specific training in Chinese herbal medicine. At present, there are no registered Chinese medicinal products that can be sold over the counter. Single substances are combined according to a special framework to compose such individual prescriptions. Standard prescription combinations, socalled classical formulas, which have been composed by famous doctors in the past, serve as starting points and as guidelines [6]. Well-trained medical or non-medical herbal practitioners in Switzerland know and work with around 250-350 individual medicinal products and around 100-200 classical formulas.

The traditional form of application is the decoction, which is prepared by cooking a mixture of crude drugs. Because the preparation of such decoctions is time-consuming, new forms of application have been developed. Today, the most popular of these 'modern' forms is dried extract powder, commonly referred to as granules [7], which were developed in Taiwan approximately 50 years ago. In Switzerland, an estimated $80 \%$ of all Chinese herbal medicine prescriptions are taken in granular form [8].

The benefit of granules is due to the fact that all individual medicinal substances are available as single granules and, similarly to crude drugs, can thus be combined to compose individualised prescriptions. This enables practitioners to issue patient-tailored prescriptions. Further- more, besides single substances, classical formulas can also be prepared in granular form by cooking the crude herbal ingredients of the classical formula together and preparing granular extracts from such decoctions. Hence, both single substances as well as classical formulas are available in granular form. As is demonstrated below, single herbs and classical formulas are often combined in clinical practice.

Other forms of application of Chinese medicine in Switzerland are crude drugs and so-called hydrophilic tinctures. Hydrophilic tinctures are prepared from alcohol tinctures in which the alcohol is replaced by glycerine. Their benefit in comparison to the crude drug decoctions and the granules is their ease of administration due to their relatively sweet taste. In contrast, the taste of crude herb decoctions and granules is generally quite unpalatable and thus influences compliance.

So far, the habits of prescription in regard to Chinese herbal medicines in Switzerland have not been looked at. It is not clear if the medical and non-medical practitioners of Chinese medicine prescribe primarily individualised prescriptions composed entirely of single substances or if classical prescriptions, with or without modifications, are more commonly applied. Furthermore, there are no studies that investigate which medicinal substances are most commonly applied or what the average daily dosage for granules is.

\section{Material and Methods}

Data

A random sample of 998 orders including 1,053 prescriptions for human patients dating between July 2008 and June 2009 was drawn from about 50,000 orders in the database of Lian Chinaherb AG, Wollerau, one of the largest pharmacies of Chinese herbs in Switzerland. The following information was used: product numbers of single herbs and formulas, their respective amount (weight), dosage instructions, the gender of the patient, and the country of origin of the practitioner.

Formulas were split up into their single ingredients for calculations of numbers of herbs per prescription and further analysis. The daily dosage was stated for most of the granular prescriptions. The duration of intake was deduced from the total amount of the prescription.

The origin of the practitioner was coded as Asian or non-Asian according to the name. Naturally, not every practitioner of Asian origin had completed their training in Asia, and not every Swiss or European practitioner had completed their training outside Asia; however, this was found to be true for the majority ( $>90 \%$ ), as estimated from a sample of 45 non-Asian and 36 Asian practitioners.

\section{Cluster Analysis}

The presence or absence of a herb in a prescription was coded as 1 or 0 , respectively, resulting in a binary data set. The Jaccard similarity coefficient and complete linkage method were used to combine single herbs (total occurrence in all prescriptions $\geq 10$ ) into clusters.

\section{Nomenclature}

Names of herbs and composition of formulas are used according to Bensky $[6,9]$. For herbs, the Chinese (Pinyin) and Latin names are listed, for formulas the Chinese (Pinyin) and English notations. All ingredients are referred to as herbs for reasons of simplicity, although not all products are parts of plants, but some are fungi, minerals, or of animal origin. 
Software

For statistical analysis, SPSS Statistics 17.0 (SPSS, Zurich, Switzerland) and r 2.5.1 (www.r-project.org) were used.

\section{Results}

\section{Prescriptions, Patients, and Practitioners}

The data set consisted of 998 orders including 1,053 prescriptions. Thus, most orders consisted of one prescription. When several prescriptions were ordered for the same patient, it was indicated that they were meant to be taken or used: a) one in the first and one in the second part of the menstrual cycle, b) one internally and one externally, c) one in the morning, one at noon, and one in the evening, or d) one regularly and one for acute conditions.

$47.4 \%$ of the orders (499) were placed by practitioners of Asian origin and $52.6 \%$ (554) by those of non-Asian origin. $74.3 \%$ (782) were prescribed for female patients, $24.8 \%$ (261) for male patients (for the remaining 10 or $0.9 \%$ the gender was unknown). The indications for which the herbs were used could not be analysed since they did not have to be stated by the practitioners during the time period in which data was collected.

\section{Composition of Prescriptions}

$96.7 \%$ of the prescriptions $(1,018)$ were composed of granules and $3.3 \%$ (35) were composed of crude herbs. $1.8 \%$ (19) were packed in capsules, and $1.3 \%$ (14) were specifically marked for external use. $46.8 \%$ of the prescriptions (493) were composed of single herbs only while $53.2 \%$ (560) were composed of pre-made classical formulas in granular form (with or without the addition of single herbs). It has to be noted that it is possible to add herbs to a pre-made formula, but when a practitioner wants to take out a herb, they have to compose the diminished formula from single herbs as it is not possible to remove individual herbs from a premade classical prescription. 427 prescriptions were based on one pre-made classical formula, but combinations of several formulas were also found: 118 prescriptions contained two formulas, 13 three formulas, and 2 four formulas.

The average number of herbs per prescription was 12 (minimum 1, maximum 37, median 12; fig. 1). The average daily dosage for granules - calculated on the basis of 944 prescriptions for which dosages were stated - was $8.7 \mathrm{~g}$ (minimum $1 \mathrm{~g}$, maximum $24 \mathrm{~g}$, median $9 \mathrm{~g}$ ). On average, the granular prescription was dosed to last for 13.9 days (minimum 1, maximum 115, median 12.5 days).

A linear regression model showed that the average daily dosage depended on the origin of the practitioner, the gender of the patient, and the number of herbs in the prescription (table 1). Asian practitioners prescribed higher dosages than non-Asians, male patients received higher dosages than females, and the larger the number of herbs in one prescription, the higher was the daily dosage.

\section{Most Frequently Used Herbs and Formulas}

Table 2 shows the most frequently used herbs. More than one-third of the prescriptions contained dang gui (Angelicae Sinensis Radix), fu ling (Poria), bai shao (Paeoniae Radix Alba), or gan cao (Glycyrrhizae Radix et Rhizoma). When prescriptions based only on single herbs and prescriptions based on formulas were compared, the most frequently used herbs were basically the same, except for hong shen (Ginseng Radix et Rhizoma Rubra) which was frequently included in pre-made formulas but not in prescriptions based on single herbs, in which dang shen (Codonopsis Radix) was often used.

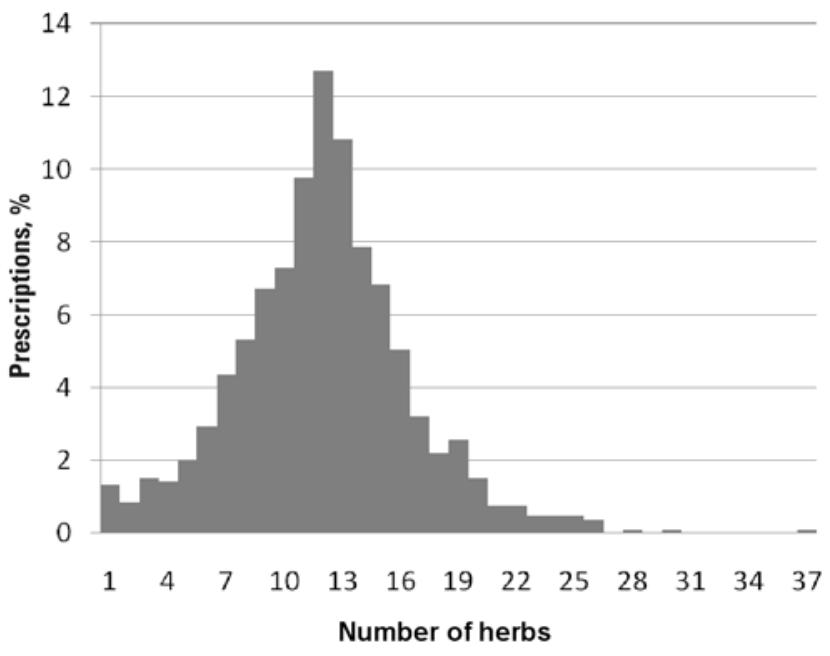

Fig. 1. Number of herbs per prescription (formulas were split up into their respective single herbs).
Table 1. Linear regression model for the daily dosage ${ }^{a}$

\begin{tabular}{|c|c|c|c|c|}
\hline \multirow[t]{2}{*}{ Parameter } & \multirow{2}{*}{$\begin{array}{c}\text { Regression } \\
\text { coefficient }\end{array}$} & \multicolumn{2}{|c|}{ 95\% confidence interval } & \multirow[t]{2}{*}{ Significance } \\
\hline & & lower & upper & \\
\hline Constant term & 7.797 & 7.191 & 8.402 & 0.000 \\
\hline Origin of practitioner ${ }^{b}$ & -0.772 & -1.149 & -0.395 & 0.000 \\
\hline Gender of patient $\mathrm{t}^{\mathrm{c}}$ & 0.650 & 0.216 & 1.085 & 0.003 \\
\hline Number of herbs in prescription & 0.091 & 0.049 & 0.133 & 0.000 \\
\hline \multicolumn{5}{|c|}{$\begin{array}{l}{ }^{\mathrm{a}} \text { On the basis of } 935 \text { cases, } \mathrm{r} \text {-square } 0.047 . \\
\text { bPractitioner Asian }=0 \text {, non-Asian }=1 . \\
{ }^{\mathrm{c}} \text { Patient female }=0 \text {, male }=1 .\end{array}$} \\
\hline
\end{tabular}


Table 2.

Most commonly used herbs

(top 30 in 1,053 prescriptions)
Table 3.

Most commonly used formulas $(2.5 \%$ or more frequent in 560 prescriptions based on formulas)

\begin{tabular}{lccl}
\hline Herb & Frequency & Percentage, \% & Category: herbs that ... \\
\hline dang gui (Angelicae Sinensis Radix) & 498 & 47.3 & tonify blood \\
fu ling (Poria) & 473 & 44.9 & drain dampness \\
bai shao (Paeoniae Radix Alba) & 436 & 41.4 & tonify blood \\
gan cao (Glycyrrhizae Radix et Rhizoma) & 371 & 35.2 & tonify qi \\
bai zhu (Atractylodis Macrocephalae Rhizoma) & 346 & 32.9 & tonify qi \\
chai hu (Bupleuri Radix) & 305 & 29.0 & release the exterior \\
chuan xiong (Chuanxiong Rhizoma) & 285 & 27.1 & invigorate the blood \\
zhi gan cao (Glycyrrhizae Radix et Rhizoma & 265 & 25.2 & tonify qi \\
$\quad$ Praeparata) & & & \\
huang qi (Astragali Radix) & 244 & 23.2 & tonify qi \\
shu di huang (Rehmanniae Radix Praeparata) & 213 & 20.2 & tonify blood \\
sheng di huang (Rehmanniae Radix) & 207 & 19.7 & cool blood \\
sheng jiang (Zingiberis Rhizoma Recens) & 204 & 19.4 & release the exterior \\
chen pi (Citri Reticulatae Pericarpium) & 188 & 17.9 & regulate qi \\
huang qin (Scutellariae Radix) & 186 & 17.7 & clear heat and dry dampness \\
da zao (Jujubae Fructus) & 180 & 17.1 & tonify qi \\
hong shen (Ginseng Radix et Rhizoma Rubra) & 174 & 16.5 & tonify qi \\
mu dan pi (Moutan Cortex) & 162 & 15.4 & cool blood \\
shan yao (Dioscoreae Rhizoma) & 150 & 14.2 & tonify qi \\
suan zao ren (Ziziphi Spinosae Semen) & 149 & 14.2 & nourish the heart and calm the \\
& & & spirit \\
fang feng (Saposhnikoviae Radix) & 142 & 13.5 & release the exterior \\
shan zhu yu (Corni Fructus) & 140 & 13.3 & stabilise and bind \\
gou qi zi (Lycii Fructus) & 139 & 13.2 & tonify blood \\
xiang fu (Cyperi Rhizoma) & 137 & 13.0 & regulate qi \\
bo he (Menthae Herba) & 129 & 12.3 & release the exterior \\
ban xia (Pinelliae Rhizoma) & 128 & 12.2 & transform phlegm-cold \\
jie geng (Platycodonis Radix) & 128 & 12.2 & transform phlegm-cold \\
ze xie (Alismatis Rhizoma) & 122 & 11.6 & drain dampness \\
dan shen (Salviae Miltiorrhizae Radix et Rhizoma) & 121 & 11.5 & invigorate the blood \\
mai men dong (Ophiopogonis Radix) & 116 & 11.0 & tonify yin \\
gui zhi (Cinnamomi Ramulus) & 113 & 10.7 & release the exterior \\
\hline
\end{tabular}

\begin{tabular}{|c|c|c|c|}
\hline Formula & Frequency & Percentage, $\%$ & Category: formulas that ... \\
\hline gui pi tang (Restore the Spleen Decoction) & 35 & 6.3 & tonify qi and blood \\
\hline xiao yao san (Rambling Powder) & 31 & 5.5 & regulate and harmonise liver and spleen \\
\hline $\begin{array}{l}\text { liu wei di huang wan (Six Ingredient Pill } \\
\text { with Rehmannia) }\end{array}$ & 26 & 4.6 & tonify yin \\
\hline $\begin{array}{l}\text { jia wei xiao yao san (Augmented Rambling } \\
\text { Powder) }\end{array}$ & 25 & 4.5 & regulate and harmonise liver and spleen \\
\hline yu ping feng san (Jade Windscreen Powder) & 23 & 4.1 & stabilise the exterior and the lungs \\
\hline $\begin{array}{l}\text { du huo ji sheng tang (Angelica Pubescens } \\
\text { and Sangjisheng Decoction) }\end{array}$ & 17 & 3.0 & dispel wind-dampness \\
\hline $\begin{array}{l}\text { tian wang bu xin dan (Emperor of Heaven's } \\
\text { Special Pill to Tonify the Heart) }\end{array}$ & 16 & 2.9 & nourish the heart and calm the spirit \\
\hline suan zao ren tang (Sour Jujube Decoction) & 16 & 2.9 & nourish the heart and calm the spirit \\
\hline $\begin{array}{l}\text { yin qiao san (Honeysuckle and Forsythia } \\
\text { Powder) }\end{array}$ & 16 & 2.9 & release exterior wind-heat \\
\hline $\begin{array}{l}\text { chai hu shu gan san (Bupleurum Powder to } \\
\text { Spread the Liver) }\end{array}$ & 15 & 2.7 & regulate and harmonise liver and spleen \\
\hline $\begin{array}{l}\text { bu zhong yi qi tang (Tonify the Middle and } \\
\text { Augment the Qi Decoction) }\end{array}$ & 14 & 2.5 & tonify qi \\
\hline $\begin{array}{l}\text { tao hong si wu tang (Four Substance De- } \\
\text { coction with Safflower and Peach Pit) }\end{array}$ & 14 & 2.5 & tonify blood \\
\hline $\begin{array}{l}\text { xue fu zhu yu tang (Drive Out Stasis in the } \\
\text { Mansion of Blood Decoction) }\end{array}$ & 14 & 2.5 & $\begin{array}{l}\text { invigorate the blood and dispel blood } \\
\text { stasis }\end{array}$ \\
\hline
\end{tabular}

Table 3 lists the most commonly used formulas. Gui pi tang (Restore the Spleen Decoction) was used most frequently, unless the two similar prescriptions xiao yao san (Rambling Powder) and jia wei xiao yao san (Augmented Rambling Powder) are counted together.

\section{Combinations of Herbs}

Cluster analysis of 177 herbs resulted in combination of known couples of herbs, e.g. tao ren (Persicae Semen) and hong hua (Carthami Flos), mu li (Ostreae Concha) and long gu (Fossilia Ossis Mastodi), mo yao (Myrrha) and ru xiang (Olibanum), ban xia (Pinelliae Rhizoma) and chen pi (Citri 
A

chen pi (Citri Reticulatae Pericarpium) ban xia (Pinelliae Rhizoma) zhu ru (Bambusae Caulis in Taenia) shen qu (Massa Medicata Fermentata) mai ya (Hordei Fructus Germinatus) shan zha (Crataegi Fructus)

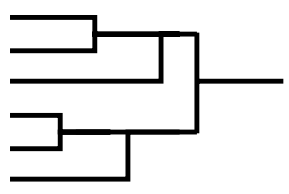

\section{B}

used. Insurance companies may be a poor data source since not all patients have an insurance covering Chinese medicine and data may be difficult to access. Analysing prescriptions of practitioners may result in describing an individual practitioner's preferences for certain herbs or formulas instead of giving an overview of prescription patterns in Switzerland. We therefore chose to analyse a sample of orders placed at one of the largest pharmacies selling Chinese herbs. Some pharmacies specialise in certain preparations that are not included in our sample, e.g. hydrophilic solutions; therefore, we cannot make any statements about the frequency of usage of other pharmaceutical forms than granules. Obviously, only herbs that are available can be ordered, and there may be a slight variation in the choice of rare herbs in different pharmacies. Thus, we mainly concentrated on the usage of the most common single herbs and formulas.

The average number of herbs per prescription in our sample was 12 , with a maximum of 37 , which seems to be a rather large number. A study investigating the composition of 11,810 formulas from 13 medical classics, however, found that about $92 \%$ contained 1-13 herbs and that the maximum was 40 herbs in one formula [10]. Herb pairs are used for mutual enhancement, assistance, and restraint, and they display special features which distinguish them from random pairs [11]. Using cluster analysis, we investigated which herbs were often combined in prescriptions. Herbs in our sample were clustered to well-known couples and groups $[6,12]$.

The average daily dosage of granules prescribed was $8.7 \mathrm{~g}$, corresponding to a medium dosage [8]. In clinical studies in Japan, where granules are commonly used, dosages of 6.0-9.0 g were applied [13-16]. The daily dosage in our sample was higher when the practitioner was of Asian origin compared to non-Asian origin. This could either reflect differences in the education of the practitioners in regard to dosing of granules or differences in patients, e.g. patients with certain conditions could preferably choose to visit a Chinese medical centre. However, since the country in which practitioners had actually received their education as well as the diagnosis of the patients were not definitely known, we abstained from further analysis of this aspect.

Prescriptions of Chinese herbs are often investigated for special groups, e.g. patients with rhinitis [17], menopause $[18,19]$, or patients in a certain hospital [20]. The diagnoses for the recipients of the prescriptions in our analysis are unknown, which makes comparisons with most studies difficult. However, one study from Taiwan that analysed data from the national health insurance reimbursement database also found jia wei xiao yao san (Augmented Rambling Powder), yin qiao san (Honeysuckle and Forsythia Powder), suan zao ren tang (Sour Jujube Decoction), 
and tian wang bu xin dan (Emperor of Heaven's Special Pill to Tonify the Heart) amongst the most frequently used formulas [21]. 7 out of the top 10 herbs in our sample were from the tonifying category and are present in many formulas. A similar result regarding the most frequently used herbs was found when the treatment of drug addiction with Chinese medicine was investigated [22].

Apart from prescriptions composed of single herbs or based on one classic herbal formula, we also found prescriptions composed of several formulas. Combinations (of small formulas) have a long tradition, e.g. ba zhen tang (Eight Treasure Decoction) is composed of the two smaller classical formulas si jun zi tang (Four Gentlemen Decoction) and si wu tang (Four Substance Decoction). Furthermore, even though the composition of patient prescriptions from classical formulas is not documented well in standard textbooks on Chinese medicine, this method of prescribing Chinese medicine is being practiced in Taiwan [7,21].
Patients in countries dominated by a western healthcare system consider Chinese medicine to be a complementary rather than an alternative form of treatment [23, 24]. Since the majority of patients even in countries like Japan and Malaysia do not tell their physician that they are using CAM including herbal medicine $[25,26]$, we may expect a similar situation in Switzerland. For the patients' safety, it will be important to identify the commonly combined conventional drugs and Chinese herbs in order to study possible interactions of their respective ingredients. Some of the research on Chinese herbal medicine has already started to focus on this topic [27-29].

\section{Disclosure Statement}

SK, who initiated the study, collected, and analysed the data, and DZ, who participated in the analysis, received no financial support for this work. SB, who wrote the introduction and contributed to the discussion, has a parttime job (30\%) at Lian Chinaherb AG.

\section{References}

1 Saller R: Complementary medicine in the federal constitution: the Swiss population has decided. Forsch Komplementmed 2009; 16:216.

2 Déglon-Fischer A, Barth J, Ausfeld-Hafter B: Complementary and alternative medicine in primary care in Switzerland. Forsch Komplementmed 2009;16:251-255.

3 Eidgenössisches Departement des Innern: Erläuternder Bericht: Ordentliche Revision des Bundesgesetzes über Arzneimittel und Medizinprodukte (Heilmittelgesetz, HMG). October 2009. www.admin.ch/ch/d/gg/pc/ documents/1636/Bericht.pdf.

$\checkmark 4$ Maxion-Bergemann S, Bornhöft G, Sonderegger E, Renfer A, Matthiessen PF, Wolf U: Traditional Chinese medicine (phytotherapy): health technology assessment report selected aspects. Forsch Komplementmed 2006;13(suppl 2):30-41.

-5 Ehling D: Oriental medicine: an introduction. Altern Ther Health Med 2001;7:71-82.

6 Bensky D, Barolet R: Chinese Herbal Medicine: Formulas and Strategies, ed 1. Seattle, Eastland Press, 1990.

7 Brand E: The granule revolution. Chinese Medicine Times 2008;3

8 Becker S: Dosierung von Granulaten. Extrakt 2009;1:10-16.

9 Bensky D, Clavey S, Stoger E: Materia Medica: Chinese Herbal Medicine, ed 3, revised. Seattle, Eastland Press, 2004.

10 Yi YD, Chang IM: An overview of traditiona Chinese herbal formulae and a proposal of a new code system for expressing the formula titles. Evid Based Complement Alternat Med 2004;1:125-132.
Ung CY, Li H, Cao ZW, Li YX, Chen YZ: Are herb-pairs of traditional Chinese medicine distinguishable from others? Pattern analysis and artificial intelligence classification study of traditionally defined herbal properties. J Ethnopharmacol 2007;111:371-377.

12 Sionneau P: Dui Yao. The Art of Combining Chinese Medicinals, ed 4. Boulder, Blue Poppy Press, 2002

13 Ohno S, Suzuki T, Dohi Y: The effect of bakumondo-to on salivary secretion in Sjögren syndrome. Ryumachi 1990;30:10-16.

14 Ikeda N, Hayasaka S, Nagaki Y, Hayasaka Y, Kadoi C, Matsumoto M: Effects of kakkon-to and sairei-to on aqueous flare elevation after complicated cataract surgery. Am J Chin Med 2002;30:347-353.

15 Ushiroyama T, Sakuma K, Ueki M: Efficacy of the kampo medicine xiong-gui-tiao-xueyin (kyuki-chouketsu-in), a traditional herbal medicine, in the treatment of maternity blues syndrome in the postpartum period. Am J Chin Med 2005;33:117-126.

16 Miyaoka T, Furuya M, Yasuda H, Hayashida M, Nishida A, Inagaki T, Horiguchi J: Yigan san as adjunctive therapy for treatmentresistant schizophrenia: an open-label study. Clin Neuropharmacol 2009;32:6-9.

$\checkmark 17$ Kung YY, Chen YC, Hwang SJ, Chen TJ, Chen FP: The prescriptions frequencies and patterns of Chinese herbal medicine for allergic rhinitis in Taiwan. Allergy 2006;61:1316-1318.

18 Chen LC, Wang BR, Chen IC, Shao CH: Use of Chinese herbal medicine among menopausal women in Taiwan. Int J Gynaecol Obstet 2009;109:63-66.

19 Yang YH, Chen PC, Wang JD, Lee CH, Lai JN Prescription pattern of traditional Chinese medicine for climacteric women in Taiwan. Climacteric 2009;12:541-547.
20 Chen LC, Wang BR, Chou YC, Tien JH: Drug utilization pattern of Chinese herbal medicines in a general hospital in Taiwan. Pharmacoepidemiol Drug Saf 2005; 14:651-657.

21 Hsieh SC, Lai JN, Lee CF, Hu FC, Tseng WL, Wang JD: The prescribing of Chinese herbal products in Taiwan: a cross-sectional analysis of the national health insurance reimbursement database. Pharmacoepidemiol Drug Saf 2008;17:609-619.

22 Min X, Lee DT, Jinhua X, Wenjun D, Li C, Bin D, Pingxiang D, Wingho L, Xiaoyin T, Xiaohui Z: A database on treating drug addiction with traditional Chinese medicine. Addiction 2007;102:282-288.

23 Loh CH: Use of traditional Chinese medicine in Singapore children: perceptions of parents and paediatricians. Singapore Med J 2009;50:1162-1168.

24 Klein SD: Why patients choose acupuncture or qigong, and what they expect from the treatment. Dtsch Zschr Akup 2009;4:18-23.

25 Hori S, Mijaylov I, Vasconcelos JC, McCoubrie M: Patterns of complementary and alternative medicine amongst outpatients in Tokyo, Japan. BMC Complement Altern Med 2008;8:14.

26 Saw JT, Bahari MB, Ang HH, Lim YH: Herbal use amongst multiethnic medical patients in Penang Hospital: pattern and perceptions. Med J Malaysia 2006;61:422-432.

27 Fugh-Berman A: Herb-drug interactions. Lancet 2000;355:134-138.

28 Li CG, Yang LP, Zhou SF: Interactions between Chinese herbal medicines and drugs. Aust J Acupunct Chin Med 2007;2:17-24.

29 Chan E, Tan M, Xin J, Sudarsanam S, Johnson DE: Interactions between traditional Chinese medicines and Western therapeutics. Curr Opin Drug Discov Devel 2010;13:50-65. 